\title{
Design and Implementation of Renewable Hydrogen Fuel Cell Vehicles
}

\author{
Kary Thanapalan $\uparrow^{*}$, Jonathan Williams * , Giuliano Premier ${ }^{*}$, Alan Guwy ${ }^{*}$ \\ *Sustainable Environment Research Centre (SERC), \\ Renewable Hydrogen Research \& Demonstration Centre, University of Glamorgan, \\ Baglan Energy Park, Baglan, Port Talbot, SA12 7AX, UK, \\ $\dagger$ Phone/Fax number: +44(0)1639 814510, E-mail: kthanapa@glam.ac.uk \\ \# Advanced Energy Systems Centre, Faculty of Advanced Technology, \\ University of Glamorgan, Pontypridd, CF37 1DL, UK
}

\begin{abstract}
In this paper, a systematic approach for investigating a hydrogen fuel cell hybrid vehicle system is considered. This approach involves developing a mathematical model incorporating renewable hydrogen production, storage and refuelling of the fuel cell vehicle system. The University of Glamorgan's (UOG) Sustainable Environment Research Centre (SERC) have developed the UK's first alternative energy refuelling facility at the University's Hydrogen Centre in Baglan. Hydrogen produced from renewable energy on-site will be use to refuel the UOG, Faculty of Advanced Technology, Hydrogen Bus (UOGHB). The simulation model is used to analyse the effect of operating conditions and energy demand of the UOGHB. Comparisons are made between the simulation results from the mathematical model and UOGHB experimental data. A general agreement exists but where disagreements and anomalies occur, reasoned arguments are presented in explanation. The model represents a reasonable overall representation of the UOGHB. This model can be used for controller development, to improve operational quality and performances.
\end{abstract}

\section{Key words}

Hydrogen Fuel cell Vehicles, Hybrid system, Modelling, Model validation, Power system

\section{Introduction}

The global aspiration to increased affluence, welfare and consumerism, while accommodating increased populations, will almost certainly result in increased global energy demand. Unless this demand can be met, the number of people who will be affected by energy shortage is likely to increase several folds. Energy shortages would be further exacerbated by fiscal and economic measures which may be required to mitigate green house gas (GHG) effects caused by burning fossil fuels. Hydrogen as an energy carrier is of considerable relevance in such circumstances, primarily because it may be produced from several renewable resources, through a number of technological routes [1]. Many of the renewable routes to hydrogen are still at the research and development stage, e.g. bio-hydrogen production from various biomass feeds, including food, co-products, energy crops and sewage sludge. However, it is important to realise that hydrogen energy is still relatively expensive to produce, install, operate and maintain. However, the gap is narrowing, particularly if externalities such as GHG are costed for all, including fossil fuels. Hydrogen as a fuel still has significant progress to make before realizing an economically feasible and safe vehicle [2]. The objective of this work is to investigate energy efficient hydrogen fuel cell hybrid vehicle systems which are less expensive to operate, and can be used as an alternative to fossil fuel vehicles.

Fuel cell (FC) based vehicles are increasingly being researched to satisfy the market need for a low emission means of transportation. Besides being a green mode of transportation, fuel cell based vehicles also promise efficient and quiet operation, which makes them an attractive proposition [3], [4]. However, in order to have an efficient economic fuel cell hybrid vehicle, it is important that the fuel consumption rate be kept low and that the energy loss be minimized. Furthermore, energy requirements for the vehicle need to be minimized [5].

This work address the issues relating to the development of new low emissions tribrid vehicles through the use of new technologies and materials along with the use of renewable energy. In particular, the paper will focus on the development and simulated implementation of renewable hydrogen fuel cell tribrid vehicles. The main purpose of the paper is to employ a simulation model for a generic hydrogen fuel cell tribrid vehicle with reference to the UOGHB. The model is then used to analyse and improve the performance of the vehicle. A description of the powertrain topologies and experimental setup are described in Section 2 and followed by the simulation model of a hydrogen fuel cell vehicle in Section 3 . Finally, validation of the hydrogen fuel cell vehicle (HFCV) is presented through the simulation results and brief analyses of these results are described in Section 4. 


\section{Experimental setup}

The vehicle studied in this paper is the tribrid hydrogen fuel cell bus of the University of Glamorgan. Proton exchange membrane fuel cells consuming hydrogen produced from renewable energy sources are widely perceived as an important long-term technology for sustainable personal mobility [6]. Here we describe the development of a computer model of the fuel cell based vehicle based on the UOGHB shown in Figure.1. This model provides the basis for future math-based design, analysis and control design of fuel cell vehicles more generally.

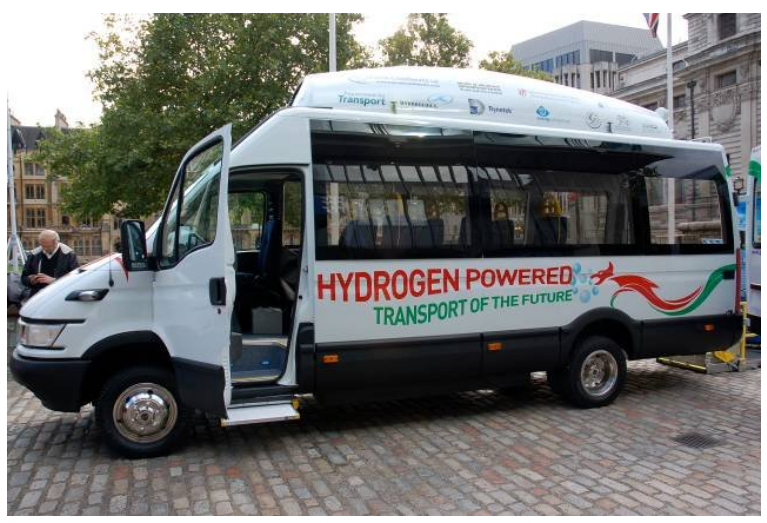

Figure.1. University of Glamorgan Hydrogen Bus

Demands for higher fuel economy, performance, and reliability, as well as reduced emissions, push industry to seek improvements in fuel cell technology. To this end, research and development is being carried out to investigate and improve the performance, stability and reliability of the fuel cell system, see for example [7], [8] [9]. The complexity of the fuel cell system requires elaborate and innovative studies for proper configuration, component sizing, and control system development to fully explore the potential of this advanced technology. A hybrid fuel cell vehicle contains an energy storage system to provide peak power and capture energy. This is typically a battery or an ultracapacitor pack or, as in the UOGHB, a combination of both. Recent studies [10], [11] have shown that the combined battery-ultracapacitor energy storage system can provide better performance and fuel economy. A quantitative analysis was performed to determine the best powertrain topologies for use in this study, based on simplicity, efficiency, mass, and cost etc. Fig. 2 shows the chosen topology. In addition to the three energy sources (fuel cell, battery and ultracapacitor) the configuration consists of a DC motor, a DC/DC converter. The whole vehicle system consists of an hydrogen supplying system, an electric drive and the vehicle body.
The powertrain of UOGHB consists of a $12 \mathrm{~kW}$ PEM fuel cell stack developed by Hydrogenics ${ }^{\mathrm{TM}}$, a $288 \mathrm{v}$, 132Amp/hr lead-acid battery pack, 375v, 21F Maxwell ${ }^{\mathrm{TM}}$ ultracapacitors and 70kW DC motor. The vehicle was tested in various conditions to verify its performance while experimental data were collected from the vehicle components.

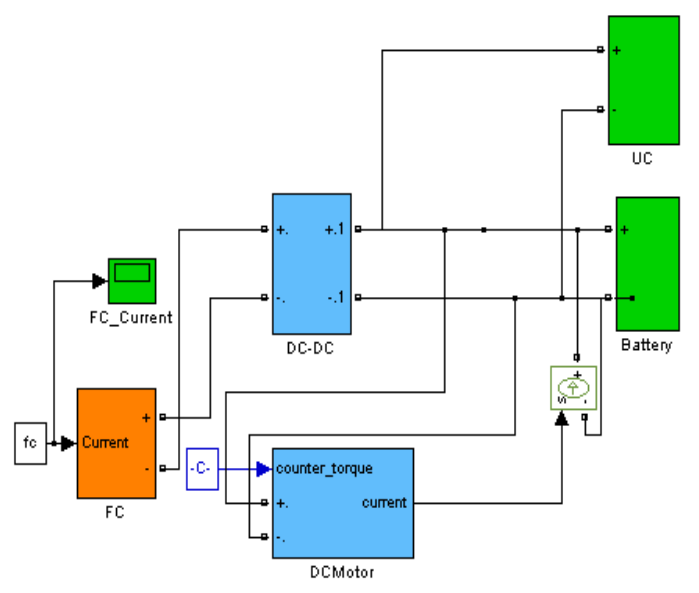

Figure.2. Energy source configuration of the UOGHB

\section{Hydrogen Fuel Cell Vehicle Model}

Utilising the UOGHB described in section 2, subsystems of a fuel cell hybrid vehicle are modelled. The hydrogen fuel cell vehicle (HFCV) model includes the following subsystems; Energy source subsystems, DC/DC converter subsystem, motor subsystem, vehicle dynamics model and a driver model. These are then lumped together in a systematic way and programmed in MATLAB/Simulink ${ }^{\mathrm{TM}}$ for a customized study.

\subsection{Energy source subsystems}

The energy source subsystem model contain three energy sources; a fuel cell, battery and ultracapacitor. A $12 \mathrm{~kW}$ PEM fuel cell stack developed by Hydrogics ${ }^{\mathrm{TM}}$ is used in the test vehicle. The PEM fuel cell model contains four interacting subsystems; cathode and anode flow, the membrane hydration, and stack voltage (see Fig.3). The electrochemical reaction at the membranes is assumed to occur instantaneously and the temperature is assumed to be constant. For the cathode and anode mass flow behaviour, the principle of conservation of mass is used to obtain governing equations [12], [13]. 


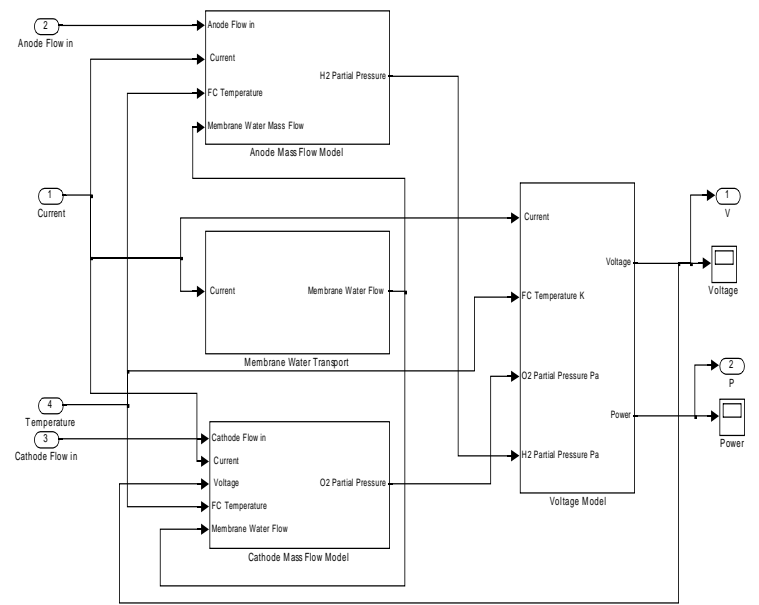

Fig.3. PEMFC system model in MatLAB/Simuliank ${ }^{\mathrm{TM}}$

Cathode mass flow:

$$
\begin{aligned}
& \dot{m}_{O_{2}}=W_{O_{2}, \text { in }}-W_{O_{2}, \text { out }}-W_{O_{2}, \text { reacted }} \\
& \dot{m}_{w, \text { ca }}=W_{v, \text { ca, in }}-W_{v, \text { ca,out }}+W_{v, \text { gen }}+W_{v, \text { mbr }}
\end{aligned}
$$

where $W_{O_{2}, \text { in }}, W_{O_{2}, \text { out }}$ and $W_{O_{2} \text {,reacted }}$ are the oxygen mass flow in, out and reacted respectively. Each of these components is expressed as follows:

$$
\begin{aligned}
W_{O_{2}, i n}= & \gamma \psi^{-1} W_{a, i n} \\
& \psi=1+k_{t .} T M_{v} M_{O_{2}}^{-1}\left(P-k_{t} T\right)^{-1}
\end{aligned}
$$

where, $W_{a, i n}$ is the inlet air flow, $\gamma$ oxygen molar fraction parameter in air, $M_{\mathrm{O}_{2}}$ oxygen molar mass, Similarly, the oxygen flow out $W_{O_{2}, \text { out }}$ is given by:

$$
W_{O_{2}, \text { out }}=\gamma \psi^{-1} W_{a, \text { out }}
$$

The rate of oxygen reacted; $W_{O_{2} \text {,reacted }}$ in the fuel cell reaction is calculated by using the electrochemical equations.

$$
W_{O_{2}, \text { reacted }}=M_{O_{2}} \frac{n \cdot i_{F C}}{4 F}
$$

where $W_{v, c a, \text { in }}$ water mass flow in, $W_{v, \text { ca,out }}$ water mass flow out, and $W_{v, \text { gen }}$ is the water generated in the fuel cell reaction are expressed by the following equations

$$
\begin{aligned}
& W_{v, \text { ca,in }}=\left(1-\psi^{-1}\right) W_{a, \text { in }} \\
& W_{v, \text { ca,out }}=\left(1-\psi^{-1}\right) W_{a, \text { out }} \\
& W_{v, \text { gen }}=M_{v} \frac{n I_{s t}}{2 F}
\end{aligned}
$$

Similarly, anode mass flow is given by:

$$
\begin{aligned}
& \dot{m}_{H_{2}}=W_{H_{2}, \text { in }}-W_{H_{2}, \text { out }}-W_{H_{2}, \text { reacted }} \\
& \dot{m}_{w, \text { an }}=W_{v, \text { an, in }}-W_{v, \text { an,out }}-W_{v, \text { mbr }}
\end{aligned}
$$

where, $W_{H_{2}, \text { in }}, W_{H_{2} \text {,out }}$ and $W_{H_{2} \text {,reacted }}$ are the hydrogen mass flow in, out and reacted respectively. Each of these terms is modelled as follows:

$$
\begin{aligned}
& W_{H_{2}, \text { in }}=\phi^{-1} \cdot W_{H_{2}, \text { an, in }} \\
& \quad \phi=1+k_{t} \cdot T M_{v} M_{H_{2}}^{-1}\left(P-k_{t} \cdot T\right)^{-1} \\
& W_{H_{2}, \text { out }}=\phi^{-1} \cdot W_{H_{2}, \text { an }, \text { out }} \\
& W_{H_{2}, \text { reacted }}=M_{H_{2}} \frac{n \cdot i_{F C}}{2 F} \\
& W_{v, \text { an }, \text { in }}=\left(1-\phi^{-1}\right) \cdot W_{H_{2}, \text { an }, \text { in }} \\
& W_{v, \text { an }, \text { out }}=\left(1-\phi^{-1}\right) W_{H_{2}, \text { an out }}
\end{aligned}
$$

Membrane hydration:

The mass flow of vapour across the membrane $W_{v, m b r}$ is calculated using mass transport principles and membrane properties [12],

$$
W_{v, m b r}=M_{v} A_{f c} n\left(\frac{n_{d} I_{s t}}{F}-D_{w} \frac{c_{v, c a}-c_{v, a n}}{t_{m}}\right)
$$

where $n$ is the number of cells, $n_{d}$ is the electro-osmotic coefficient.

Voltage Model:

The fuel cell voltage is calculated by subtracting the fuel cell losses or overvoltages from the fuel cell open circuit voltage, $E$, and is given by

$$
v_{f c}=E-v_{a c t}-v_{o h m}-v_{c o n}
$$

The total stack voltage can be calculated by multiplying the cell voltage by the number of cells of the stack,

i.e., $\quad v_{s t}=n \times v_{f c}$

where $E$ is the fuel cell open-circuit voltage and it is the maximum possible reversible voltage; $v_{a c t}$ represents the activation overpotential at the electrodes; $v_{\text {ohm }}$ represents the ohmic overpotential caused by electrical and ionic conduction loss; $v_{\text {con }}$ represents the concentration overpotential caused by mass transport limitations of the reactants to the electrodes. Each of these terms is modelled as follows: 


$$
\begin{aligned}
& E=-\frac{G^{0}(T)}{2 F}+\frac{R T}{2 F} \ln \left(\frac{p_{\mathrm{H}_{2}} p_{\mathrm{O}_{2}}}{p_{\mathrm{H}_{2} \mathrm{O}}}\right) \\
& v_{\text {act }}=-\left[\xi_{1}+\xi_{2} T+\xi_{3} T \ln \left(C_{\mathrm{O}_{2}}\right)+\xi_{4} T \ln \left(i_{F C}\right)\right] \\
& v_{\text {ohm }}=i_{F C}\left(R_{e}+R_{\text {proton }}\right) \\
& v_{\text {con }}=-B \ln \left(1-\frac{i}{i_{\max }}\right)
\end{aligned}
$$

where $\xi_{i}, R_{e}$ and $B$ are adjustable parameters. Including these parameters, the model contains several adjustable parameters. The value of the parameters cannot be determined accurately due to the fact the no unique combination of values may be identified and only their ranges can be estimated. Parameter identification /optimisation methods can be used to make the model represent the real fuel cell system acceptably. Details of parameter optimisation studies can be found in [13]. The PEMFC model presented representing the $12 \mathrm{~kW}$ PEM fuel cell stack incorporated in the UOGHB.

The second energy source is the battery. The battery pack used in the UOGHB system is a $288 \mathrm{~V}, 132 \mathrm{~A} / \mathrm{h}$ lead-acid pack. An equivalent resistance circuit model is used to represent its operation. The state-dependent internal resistance $R$, and the open circuit voltage, $E$ are lumped representations of complex chemical processes, and are known to be functions of the battery state of charge $(S)$. $S$ is the only state variable in the battery system model.

$$
\begin{aligned}
& V_{b}=E(S)-I_{b} R(S) \\
& I_{b}=-E-\left(E^{2}-4 P_{b} R\right)^{\frac{1}{2}} \cdot(2 R)^{-1} \\
& E=E_{0}-K \cdot Q(Q-i t)^{-1}+A \cdot \exp (-B \cdot i t) \\
& \langle i t\rangle=-\int_{0}^{t} I_{b} \cdot d t+Q(0) \\
& S=\left(Q_{\max }-\int_{0}^{t} I_{b} \cdot d t\right) \cdot Q_{\max }^{-1}
\end{aligned}
$$

where $V_{b}$, the terminal voltage of the battery $E$, no load voltage $I_{b}$, the battery current $P_{b}$ is the output power of the battery $Q$, battery capacity $A$, exponential voltage, and $B$ exponential capacity. This generic battery model is parameterized to represent the lead-acid battery. However, all the parameters of the model can be modified to represent a particular battery type, based on its charge and discharge characteristics.

Finally, Maxwell ${ }^{\mathrm{TM}}$ ultracapacitor modules are incorporated as the third energy source. Thus, the ultracapacitor model parameters are based on the same ultracapacitor modules, with their operation is represented by an equivalent circuit model. The model consists of an equivalent series resistance $R_{u c}$ and an ideal capacitance $C_{i d}$. Thus, the current-voltage relationship of the ultracapacitor is expressed as follows;

$$
V_{u c}=R_{u c} I_{u c}+\frac{1}{C_{i d}} \int_{0}^{t} I_{u c} d t+V_{i d}(0)
$$

where $V_{u c}$ is the voltage at the terminals of the ultracapacitor, $V_{i d}(0)$ is the initial voltage across the ideal capacitor $C_{i d}$ and $I_{u c}$ is the current flowing into the ultracapacitor. Also note that $V_{u c}(0)=V_{i d}(0)$, when $I_{u c}(0)=0$.

\subsection{DC/DC converter subsystem}

A DC/DC converter in the context of the vehicle, accepts a DC input voltage from the power sources and produces a DC output voltage. Typically the output produced from such devices is at a different voltage level than the input. DC/DC converters are used to provide power bus regulation and in this paper, a unidirectional step up DC/DC converter is used to connect the fuel cell system to the other energy sources (battery or ultracapacitor). The chosen system topology requires a voltage higher than the input and the power flow from the fuel cell side to the other energy sources. The efficiency of the DC/DC converter is defined as the ratio of output power on the battery (or ultracapacitor) side, over the input power on the fuel cell system side. By using the experimental data of voltage and current on both sides of the DC/DC converter, the corresponding efficiency is calculated and depends on the input power to the DC/DC converter.

\subsection{Motor subsystem}

The motor used in the UOGHB is a $70 \mathrm{~kW}$ DC motor. It is the means by which electrical energy is converted to mechanical energy. There are many types of DC motor and their detailed construction is complex but it is possible to derive the governing equations suitable for a satisfactory dynamic model, from basic electromagnetic relationships. In this section a simple equivalent circuit model is derived (see Fig.4.) to simulate its dynamic behaviour;

$$
\begin{aligned}
& J \frac{d \dot{\theta}}{d t}=\tau-b_{m} \dot{\theta}-\tau_{L} \\
& \tau=\kappa_{t} i \\
& V_{m}=R_{m} i+L \frac{d i}{d t}+V_{e} \\
& V_{e}=\kappa_{e} \dot{\theta}
\end{aligned}
$$


where $V_{m}, R_{m}, L$ are the motor voltage, resistance, and inductance receptively; $J$ inertia, $\quad b_{m}$ damping, $\kappa$ constant and $\kappa=\kappa_{t}=\kappa_{e}$ with the unit as $\mathrm{Vrad}^{-1} / \mathrm{sec}$

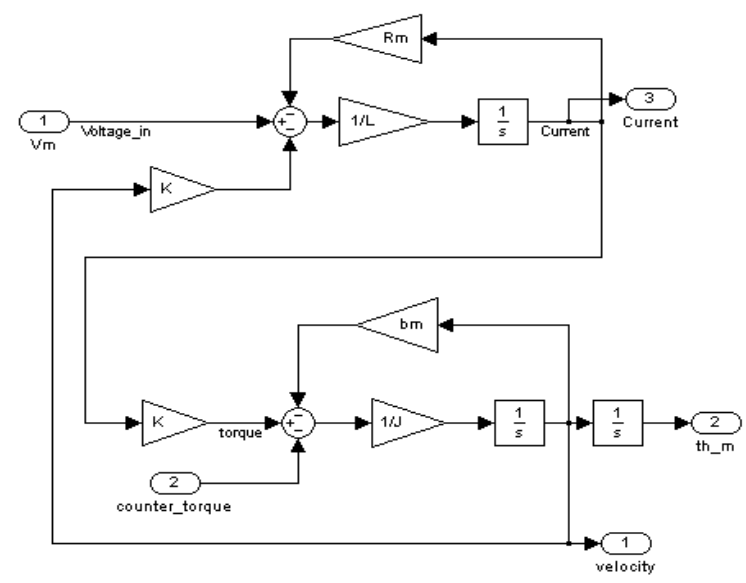

Figure.4. Equivalent circuit model of DC Motor

\subsection{Vehicle dynamics model}

In order to simulate the mechanical characteristics of the UOGHB, a simple vehicle model is developed and it contains rotational wheel dynamics and linear vehicle dynamics. The state equation of the wheel speed is written as;

$$
\frac{d \omega_{w h}}{d t}=\frac{1}{J_{r}}\left(\tau_{w h}-\tau_{b}-B_{w h} \omega_{w h}-r_{w h}\left(F_{x}+F_{r}\right)\right)
$$

where,

$$
\begin{aligned}
& F_{r}=C_{r} F_{z} \\
& F_{x}=\mu_{w h}\left(\lambda_{w h}\right) F_{z}
\end{aligned}
$$

The vehicle speed is calculated from the state equation:

$$
\frac{d v_{v}}{d t}=\frac{1}{M_{v}}\left(F_{x}-\frac{v_{v}}{\left|v_{v}\right|} F_{a}\right)
$$

\subsection{Driver model}

A driver function is constructed to cause the vehicle to follow the specified driving cycle, i.e., generates acceleration or deceleration commands to simulate a driver. Therefore, from a system point of view it can be considered as a controller. It is possible to design any of several controllers for traction and breaking etc. in this case a simple PID controller is design for demonstration purposes. It should be noted that this controller is different from the energy sources controller design. For example, controllers can be design to obtain better performance for fuel flow control or enhancement of the overall performance for the fuel cell. Details of such controller design can be found in [5], [14], [15].

So far, a hybrid electric bus model has been developed and implemented in MATLAB/Simulink (see Figure.5.) This model contain a $12 \mathrm{~kW}$ FC stack, DC/DC converter model with boost converter topologies, battery pack, ultracapacitor model, $70 \mathrm{~kW}$ DC motor and vehicle dynamics parameterised with the mechanical characteristics of the real vehicle. The vehicle model is modelled according to the same structure and it's implemented and configured in the same way as it is for the real system. This allows as carrying out further analysis for improvements.

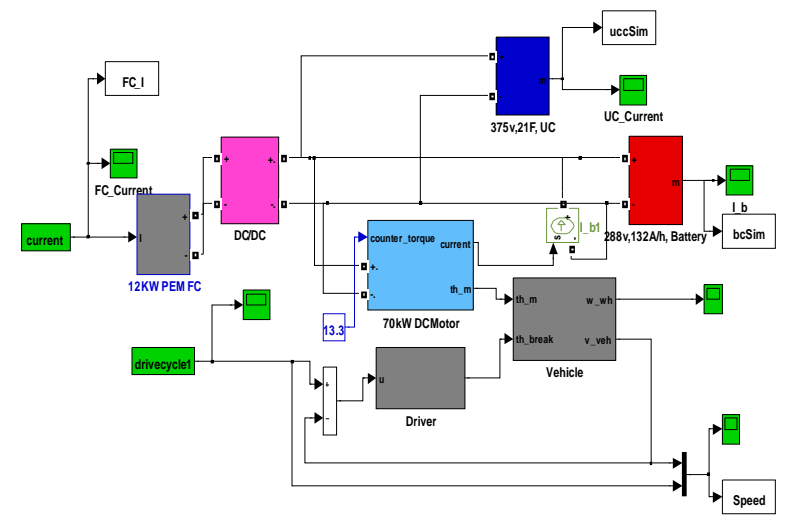

Figure.5. Hybrid Electric Bus Model

\section{Validation of the HFCV model}

The parameters of the HFCV model were based on the UOGHB. It is important to note that each subsystem is modelled and validated separately, see for example [12]. However, the HFCV simulation model needs to be checked to confirm that the overall model works properly (verified). For the purpose of the vehicle model validation, data for the fuel cell current request command is given to the simulation model (see Figure.6.)

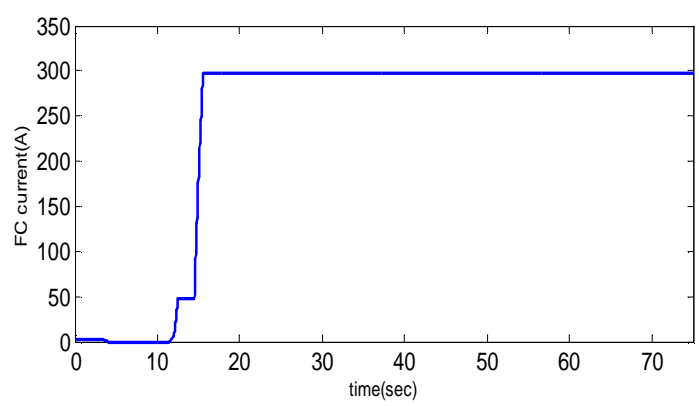

Figure.6. Vehicle system inputs 


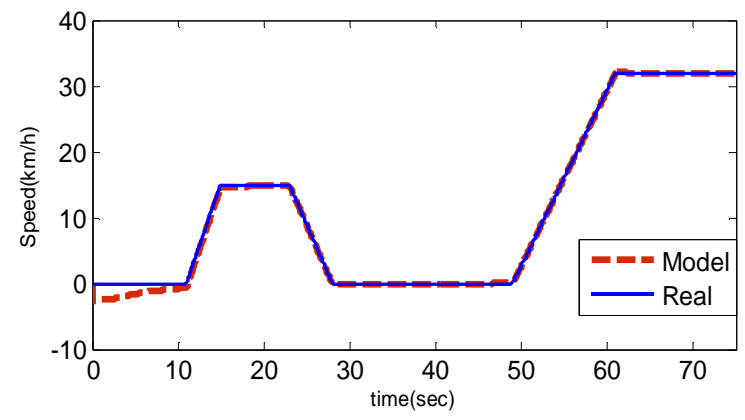

Figure.7. Overall vehicle system responses

Overall system response is presented in Figure 7. In the case of energy sources performance evaluation, we have used a current source in the model to simulate the vehicle working status. This current source represents the total current logged in the data files. Then we compared the responses of each individual source of energy. Comparison results show that there is a general agreement between the vehicle data and the simulation model results. Vehicle data were generated from the tests conducted for specific driving conditions, by driving the vehicle around the University main campus.

An extensive simulation is carried out and results for a typical case are presented in this paper as an example (see Figure.7). The simulation model response was computed using the actual measured vehicle data. Both the vehicle data and the simulation data were plotted at the same scale, which enables an easier comparison of the variables of interest. The dashed lines and solid lines indicate the simulation model and vehicle test responses respectively. There exists reasonably good correlation with the vehicle data response; however some discrepancies are evident, which might be an indication that some unstable factors in the real vehicle have not been included into the model.

\section{Concluding Remarks}

In this paper, design and implementation of a renewable hydrogen fuel cell vehicle is described. A HFCV system model has been developed for a simulation study for control analysis, configuration setup and analysis for better energy management strategies. The model was constructed based on the UOGHB. Comparisons are made between the simulation results from the mathematical model and UOGHB experimental data. Correlation, in the main, is satisfactory but anomalies are present. Possible reasons for those anomalies are suggested. Overall the model represents the UOGHB. This model can be used for math-based vehicle developments and controller design to improve system performance.

\section{Acknowledgement}

Financial support from ERDF - Cymru H2 Wales project grant is gratefully acknowledged.

\section{References}

[1] S.Cherryman., J.Maddy., F.R.Hawkes., D.L.Hawkes., R.M.Dinsdale.,A.J.Guwy.,G.C.Premier.(2004), Hydrogen and Wales: "A vision of the hydrogen economy in Wales: Placing Wales in a position to take full advantage of the hydrogen economy'. Trefforest, UK

[2] C.Dufour., T.K.Das., S.Akella. (2005), 'Real Time Simulation of Proton Exchange Membrane Fuel Cell Hybrid Vehicle', In the Proc. of Global Powertrain Congress'05, pp.1-13

[3] K.K.T.Thanapalan, G.P.Liu., J.G.Williams., B.Wang., D.Rees. (2009), 'Review and Analysis of Fuel Cell System Modelling and Control', Int. Journal of Computer Aided Engineering and Technology, vol.1, No.2, pp.145-157.

[4] S.Akella., N.Sivashankar., S.Gopalswamy. (2001), 'Model Based Systems Analysis of a Hybrid Fuel Cell Vehicle Configuration', In the Proc. of ACC'2001, pp.1777-1782

[5] K.K.T.Thanapalan., G.P.Liu., J.G.Williams., D.Rees., (2009) 'Robust Fuzzy Controller Development for A PEM Fuel Cell System', Int. Journal of Advanced Mechatronic Systems, vol.1, No.3, pp.223-230

[6] M.J.Kim., H.Peng., C.C.Lin., E.Stamos., D.Tran., (2005) Testing, Modelling, and Control of a Fuel cell Hybrid Vehicle', In the Proc. of ACC'2005, pp.3859-3864

[7] L.Chiu, B.Diong, R.Gemmen, (2004) "An Improved SmallSignal Model of the Dynamic Behaviour of PEM Fuel Cells", IEEE Trans on Industry Applications, vol 40, No 4, July/August 2004

[8] Q.Yu, A.Srivastava, S.Choe, W.Gao, (2006) "Improved modelling and control of a PEM Fuel cell power system for vehicles", In the Proc of IEEE Southeast Conf 2006, pp331-336

[9] M.DeFrancesco, E.Arato., (2002) "Start-up analysis for automotive PEM Fuel cell Systems", J.of Power Sources, Vol 108, pp 41-52, 2002

[10] R.Schupbach., J.Balda., M.Zolot., B.Kramer., (2003) "Design methodology of a combined battery-ultracapacitor energy storage unit for vehicle power management", In the Proc of 2003 IEEE Power Electronics Specialist Conference, Acapulco, 2003, pp88-93

[11] R.Schupbach., J.Balda., (2003) "The role of ultracapacitors in an energy storage unit for vehicle power management", In the Proc of 2003 IEEE Vehicular Technology Conference, Orlando, 2003, pp3236-3240

[12] K.K.T.Thanapalan., J.G.Williams., G.P.Liu., D.Rees., (2008) "Modelling of a PEM Fuel Cell System" In the proc. of IFAC World Congress'08, Seoul, Korea, 2008

[13] K.K.T.Thanapalan., B.Wang., J.G.Williams., G.P.Liu., D.Rees., (2008) "Modelling, Parameter Estimation and Validation of a 300W PEM fuel cell system", In the proc. of UKACC'08, Int. conf. on Control 2008, Manchester, $U K, 2008$

[14] J.G.Williams., G.P.Liu., S.Chai., D.Rees., (2008) "Intelligent control for improvements in PEM fuel cell flow performance", Int. Journal of Automation and Computing, 2008, 05(2), pp145-151

[15] J.G.Williams., G.P.Liu., K.K.T.Thanapalan., D.Rees., (2007) "Design and Implementation of On-line SelfTuning Control for PEM Fuel Cells" In the proc. of EVS-23; Sustainability- The future of Transportation, California, USA, 2007, pp 359-375 